\title{
CONGENITAL ABSENCE OF PAIN
}

\author{
A FAMILY STUDY \\ MOHAMMED ABDUL FATH, M. RIFAAT HASSANEIN, J. I. P. JAMES
}

From the Kuwait Orthopaedic Service

\begin{abstract}
A family study is presented in which five of the $\mathbf{1 0}$ children have congenital absence of pain, inability to sweat and mental retardation; three children have neuropathic joints. The differential diagnosis, management and prognosis of this rare disorder are discussed.
\end{abstract}

The absence of a sense of pain as an inherited condition was first described by Dearborn in 1932. There are very scanty references to it in the orthopaedic literature; Silverman and Gilden (1959) referred to the radiological changes. Whilst it is primarily a neurological disease the manifestations which usually bring the patient to hospital are orthopaedic problems: Charcot joints, apparently spontaneous fractures, trophic ulceration and scoliosis. Despite the senior author's long experience of scoliosis and an associated orthopaedic clinical genetic unit (directed by Dr Ruth Wynne-Davies) only one such child had previously been seen.

\section{THE FAMILY}

The family recently presented at the Al-Adan Hospital, Kuwait. The parents are both originally Iraqi, both are normal but are first cousins, the commonest pattern of marriage in many Arab countries. There are 10 children, seven male and three female. Amongst these children five are normal and five affected (Table I).

The father has been able to distinguish early and with ease between the normal and the abnormal: the boys quickly demonstrate their toughness in fighting since they cannot be hurt! He has also noticed in the very hot climate of Kuwait, which averages over 120 degrees Fahrenheit (40 degrees Celsius) shade temperature for three months and may go over 130 degrees Fahrenheit (50 degrees Celsius), that none of the affected children can sweat. In hot weather he has to cool them by pouring cold water on them. Despite this, the oldest girl once had convulsions, presumably from hyperthermia. In the winter, in contrast, they feel very cold and need to be kept warm with many blankets although the temperature

M. A. Fath, MSOrth (Alexandria), Registrar

Al Adan Hospital, Kuwait, Arabian Gulf.

M. R. Hassanein, FRCSEd, Consultant Orthopaedic Surgeon Kuwait Orthopaedic Hospital, PO Box 4079, Kuwait, Arabian Gulf. Professor J. I. P. James, MS, FRCS, FRCSEd, FRACS(Hon) C137, Riyadh Armed Forces Hospital, PO Box 7897, Riyadh 11159 , Kingdom of Saudi Arabia.

Requests for reprints should be sent to Professor J. I. P. James.

(C) 1983 British Editorial Society of Bone and Joint Surgery $0301-620 \mathrm{X} / 83 / 2031-0186 \$ 2.00$ is never as low as zero degrees Celsius. From this it would appear that they not only lack the sense of pain but also lack temperature control. All five affected children are mentally backward, and although the older ones can read and write they spend on average three years in each class before moving up.

Table I. The children

\begin{tabular}{|lllll|}
\hline Number & $\begin{array}{l}\text { Age } \\
\text { (years) }\end{array}$ & Sex & Normal & Affected \\
\hline 1 & 20 & Female & & $*$ \\
2 & 18 & Male & $*$ & \\
3 & 17 & Male & $*$ & \\
4 & 14 & Female & $*$ \\
5 & 13 & Male & $*$ & (undescended testicles) \\
6 & 11 & Female & $*$ & \\
7 & 8 & Male & $*$ \\
8 & 5 & Male & $*$ \\
9 & 4 & Male & $*$ \\
10 & 3 & Male & $*$ & \\
\hline
\end{tabular}

On neurological examination they are normal in motor power and reflexes. Cutaneous sensation to light touch is normal, pinprick is felt but not as pain. If the pin is pushed through the skin they are aware of an uncomfortable feeling but it is not painful. The seventh child has areas over the costal margins and thighs where he can feel pain.

\section{CASE HISTORIES}

Child 1, a girl aged 20 years who has an atrophic Charcot destruction of her right hip (Fig. 1). The hip telescopes up and down several inches and has virtually unlimited, painless movement. She has thick fissured skin on the left foot with trophic ulceration. There are Charcot changes in the ankle and foot (Figs 2 and 3). The right foot was partially amputated for gangrene which developed when traction was applied for the Charcot hip. There has recently been a painless fracture of the left tibia with abundant callus. She is extremely disabled and can only walk with assistance. 


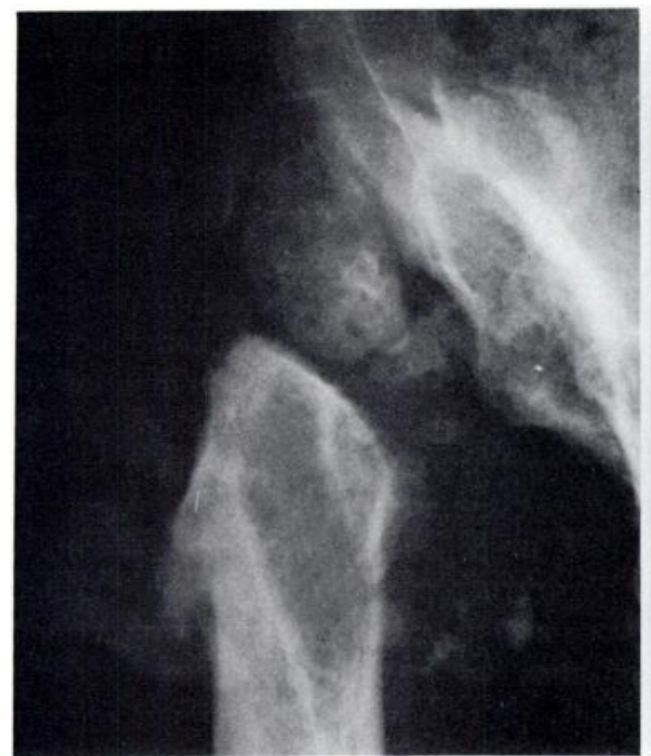

Fig. 1

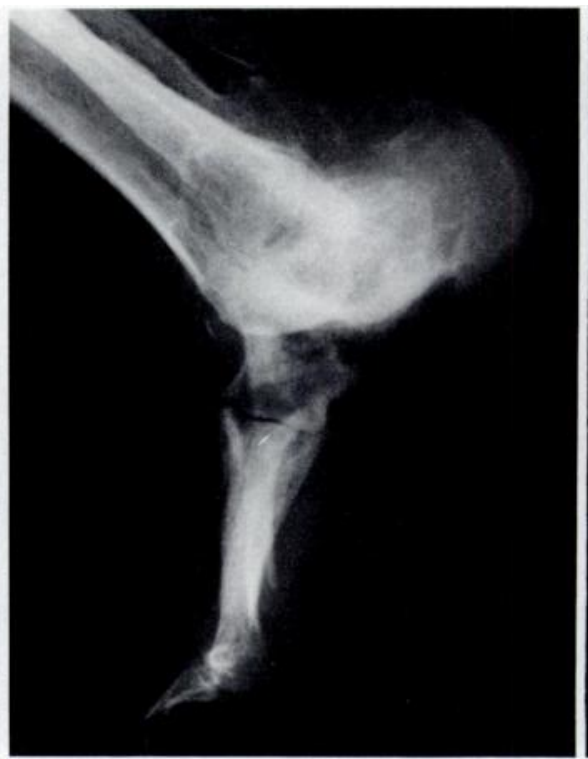

Fig. 2

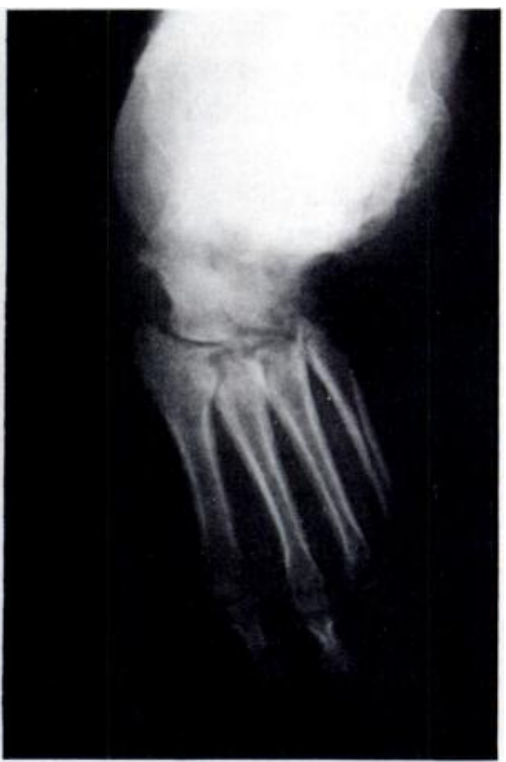

Fig. 3

A girl aged 20 years. Figure 1-Totally destroyed right hip. Figures 2 and 3-Charcot changes in the ankle and foot.

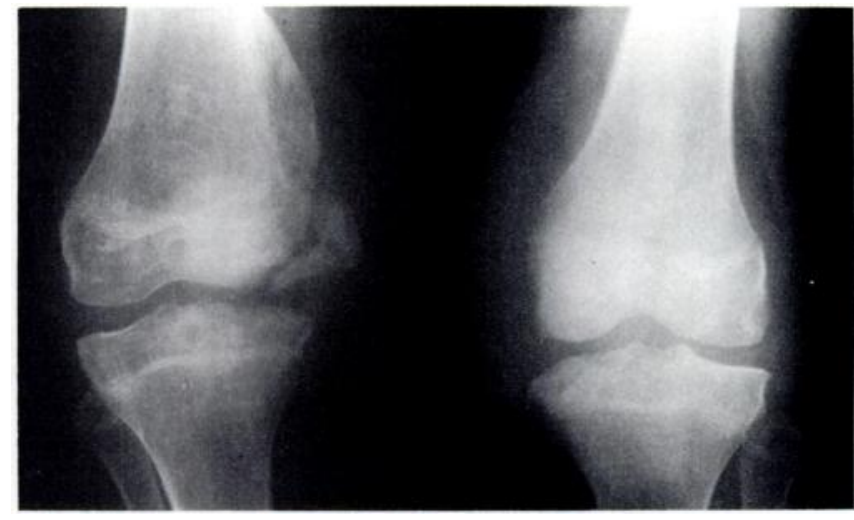

Fig. 4

A girl of 14 years with unstable Charcot knees.

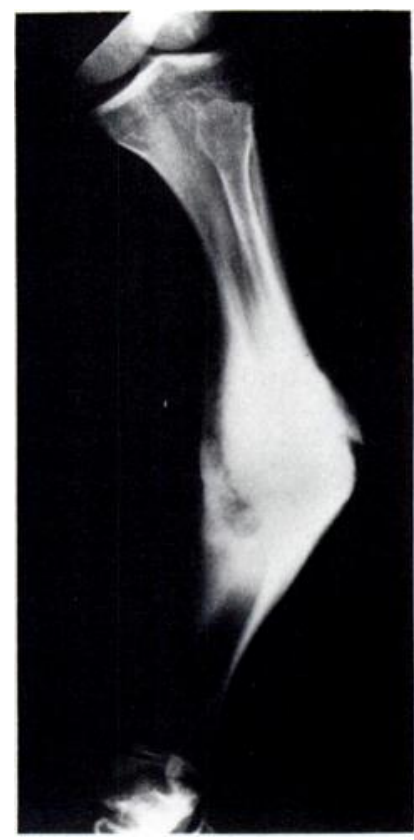

Fig. 5

A boy aged eight years with painless fractures of tibia and fibula.
Child 4, a girl aged 14 years. This girl has bilateral grossly unstable Charcot knees (Fig. 4). On the medial side of both there appears to be no ligamentous support. She has extensive anterior incisions over both knees, from arthrotomies performed in London. There is no record of why this was done nor what was found. The girl is now just able to walk.

Child 7, a boy aged eight years. He has a painless fracture of one tibia and fibula (Fig. 5). The shaft of the fibula is expanded and it looks as though the growth of the lower epiphysis might be arrested. He has recently presented with a painless fracture within the elbow; there is abundant callus and also destruction, and it would seem that these are the early changes of a Charcot joint. He has a thoracic kyphosis and a radiograph suggests $C$ harcot changes in one thoracic vertebra. The boy bites his nails right to the flesh; this is a feature of the condition and his two younger brothers do the same.

Children 8 and 9, two boys aged five and four years. To date they have no skeletal manifestations, but their nails are bitten right back. Their feet show horny skin with deep fissures and cuts which are not painful, although they walk barefoot.

\section{DISCUSSION}

Judging from the present state of the two oldest girls it would seem likely that all five affected children will become similarly disabled and will be in wheelchairs in their early twenties. The prospect of five such disabled and backward children is indeed daunting, particularly in a hot desert country such as Kuwait. No surgical treatment seems possible for the oldest girl's Charcot hip. The extraordinary instability of the second girl's knees seems to demand arthrodeses and yet surely the notorious difficulty in getting fusion would rule out any attempt. Even if it succeeded it would seem likely that other joints in the leg might soon become disabled.

Although life without pain sounds ideal, the lack of protective reflexes handicaps the afflicted children in various ways. As soon as the eruption of teeth takes place, the condition is evident by biting of the tongue, lips or fingers. Burns and multiple bruises are common 
occurrences. The infant fails to cry when hurt. Dental sepsis causes early loss of teeth. Corneal opacity may result from trauma or foreign bodies introduced in the eye.

Trauma causes fractures of the long bones, the skull and the short tubular bones of the hands and feet although the bones are not unduly fragile. However, delayed diagnosis and failure to treat these fractures result in gross deformities of the long bones and even pseudarthrosis.

In infancy epiphysial separations may occur. In early childhood the fractures take place at the metaphysis and in later childhood in the diaphysis. In adolescence and in adult life, the incidence of acute fractures decreases, as with maturity and increasing awareness the patient learns to prevent injury. Aseptic necrosis of the talus and of the femoral head may occur. Joints respond to multiple minor injuries by effusion, haemarthrosis, synovial thickening and ligamentous laxity; eventually typical neuropathic arthropathy develops. Weightbearing joints, especially the ankles, are common sites. The presence of a Charcot joint in a child should arouse suspicion of congenital indifference to pain.

Osteomyelitis of long bones is a common incidental finding in the radiographs and is seen as an area of rarefaction in the metaphysis. The bone infection is usually discovered in its chronic stage as it is indolent and painless.

Radiographic features. The radiographic abnormalities are varied. Charcot joints develop at an early age. The ankles and joints of the tarsus are the most common sites. Fractures may only attract attention because of the resulting deformity. They unite satisfactorily but malunion is common. Examination of such patients may reveal fractures, in various stages of healing, which had not previously been suspected.

Differential diagnosis. Various neurological diseases and leprosy should be considered. Early cases could be confused with the battered child syndrome.

Treatment. The patient and his parents should be educated to prevent injury. Early diagnosis and immediate treatment of fractures are important. Fractures ordinarily heal without difficulty. Osteomyelitic lesions are treated in the usual manner.

Prognosis. A normal life span can be expected for most patients, partly because of regression of the disorder and partly because of other qualities of sensation, especially intellectual awareness, taking over as substitutes.

It would seem likely that in this family this condition has been inherited by a recessive trait. Both parents are normal but are first cousins. Although the proportion of affected children is high, only one in four in recessive disease being affected, at each conception there is a one in four chance of both parents contributing the faulty gene and thus the greater number of cases in the family is explicable.

Access to world literature is limited but the authors are unaware of a similar family being reported.

\section{REFERENCES}

Dearborn GVN. A case of congenital general pure analgesia. J Nert Ment Dis 1932; 75:612-5.

Silverman FN, Gilden JJ. Congenital insensitivity to pain : a neurologic syndrome with bizarre skeletal lesions. Radiology 1959:72:176-90. 